\title{
CONSTITUINTES VOLÁTEIS DE DIFERENTES ÓRGÃOS VEGETAIS DE PIPER ADUNCUM L.
}

\section{ARTIGO ORIGINAL}

SOBRINHO, Alessandra Carla Guimarães ${ }^{1}$

SOBRINHO, Alessandra Carla Guimarães. Constituintes voláteis de diferentes órgãos vegetais de Piper aduncum L. Revista Científica Multidisciplinar Núcleo do Conhecimento. Ano 05, Ed. 10, Vol. 03, pp. 116-126. Outubro de 2020. ISSN: 24480959, Link de acesso: https://www.nucleodoconhecimento.com.br/quimica/constituintes-volateis

\section{RESUMO}

O presente trabalho teve como objetivo a análise dos constituintes voláteis presentes no concentrado volátil das espigas de Piper aduncum L. obtido através do processo de destilação-extração simultânea utilizando um aparelho de Likens-Nickerson, bem como, verificar os constituintes presentes no óleo volátil das folhas obtidos pela hidrodistillação, em aparelhos Clevenger modificados. A análise do concentrado volátil e do óleo volátil foi feita por Cromatografia gasosa acoplada à Espectrometria de Massa (CG/EM). O percentual de identificação dos constituintes na análise de óleos voláteis e concentrado volátil de Piper aduncum L. atingiu valores superiores a $85 \%$ para constituintes majoritários, piperitona, miristicina e dilapiol. A análise dos constituintes voláteis identificou 25 constituintes, sendo que 12 deles estão presentes

\footnotetext{
${ }^{1}$ Doutoranda no Programa de Pós-Graduação em Biodiversidade e Biotecnologia da Rede Bionorte no Museu Paraense Emilio Goeld / Universidade Federal do Pará, Belém - Pará, Mestra em Ciência e Tecnologia de Alimentos pelo Programa de PósGraduação em Ciência e Tecnologia de Alimentos da Universidade Federal do Pará, Belém - Pará, Bacharela em Química pela Universidade Federal do Pará, Belém Pará.
} 
em ambas as técnicas e peças vegetais utilizadas; 8 são exclusivos do concentrado volátil e 5 presentes apenas nos constituintes voláteis do óleo.

Palavras-Chave: Piper aduncum, destilação-extração, hidrodestilação, voláteis.

\section{INTRODUÇÃO}

Os vegetais são importante fonte de substâncias com ampla diversidade estrutural e de propriedades químicas que podem servir para o desenvolvimento de um grande número de fitofármacos (ALVES, 2001), assim, a busca por plantas que apresentem compostos com propriedades químicas de interesse tem sido alvo de pesquisas científicas focadas no desenvolvimento de novos fármacos menos agressivos e de reduzidos efeitos colaterais (ALI et al., 2011).

Os investimentos na pesquisa de novas drogas são crescentes (PAN et al., 2010). Todavia o processo de seleção de espécies vegetais para a pesquisa científica não é algo simples de ser feito, segundo Gyllenhaal et al., (2012), a maior probabilidade para a descoberta de novos compostos bioativos envolve a seleção com base na indicação por grupos populacionais a partir do conhecimento terapêutico construído localmente, nesse sentido estudos de plantas amazônicas, ricas em compostos bioativos, pode favorecer a descoberta de novos compostos e/ou novas fontes, fato que auxiliaria no desenvolvimento econômico e tecnológico da região, tendo em vista o potencial da flora aromática da região amazônica.

Dentre as plantas medicinais de interesse terapêutico encontra-se as da família Piperaceae, uma família tropical e subtropical, que ocorre em ambos os hemisférios terrestres, incluindo aproximadamente 4.000 espécies. Diversas espécies do gênero Piper são amplamente utilizadas na medicina popular em várias partes do mundo e têm sido relatadas por produzirem compostos com propriedades biológicas diversas como antimicrobiana, uso em problemas do trato respiratório, do aparelho digestivo, anti-inflamatória e antileucêmica (SANTOS et al., 2012). Considerando a importância biológica das espécies deste gênero, o presente trabalho objetivou estudar a presença de compostos bioativos na Piper aduncum L., conhecida pelo nome de pimenta de 
macaco através da técnica de Cromatografia Gasosa acoplada ao Espectro de Massas (CG/EM) (Figura 1), essa espécie é utilizada na medicina popular da região amazônica em várias doenças (SOUSA et al., 2008), produz óleo cujo o constituinte apresenta atividades repelente (MISNI et al., 2009), antimicrobiana (GUERRINI et al., 2009), inseticida (MESQUITA et al., 2005; SANINI et al., 2017).

Figura 1 - Resumo gráfico da análise dos comstituintes voláteis presentes na Piper aduncum L. usando Cromatografia Gasosa acoplada à Espectrometria de Massas.

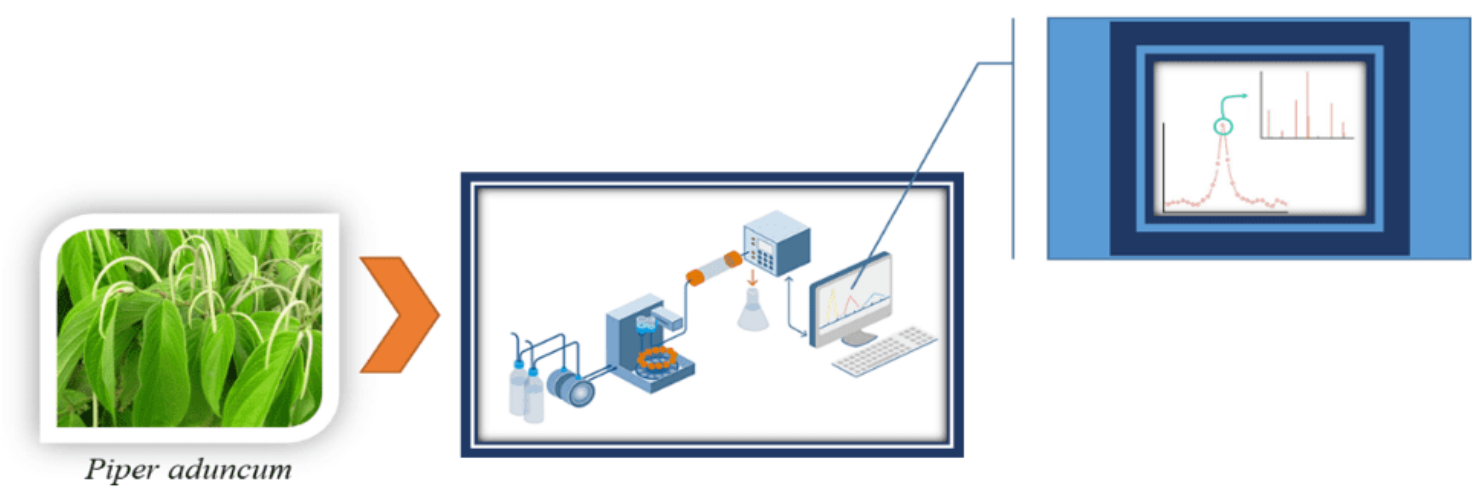

Fonte: Autor.

\section{MATERIAL E MÉTODOS}

\subsection{COLETA E PREPARAÇÃO DO MATERIAL VEGETAL}

A coleta do material botânico da espécie Piper aduncum $L$. foi realizada no município de Belém/PA, no Museu paraense Emilio Goeldi no dia 11 de setembro de 2018 às 09:30h, temperatura no local $25,6{ }^{\circ} \mathrm{C}$ e umidade $67,9 \%$, em seguido o material botânico coletado foram levados para sala climatizada com desumidificador (Figura 2). 
Figura 2 - Coleta e preparação do material botânico da espécie Piper aduncum L.

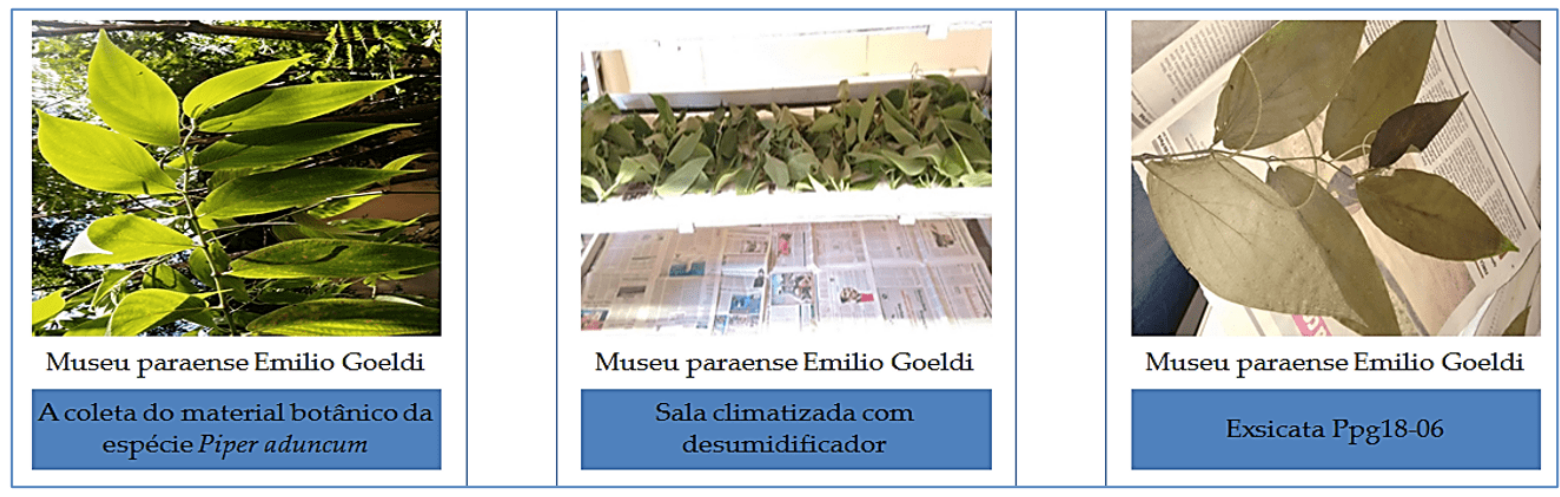

Fonte: Autor.

\subsection{OBTENÇÃO DO CONCENTRADO VOLÁTIL (AROMA)}

O concentrado volátil das espigas de Piper aduncum L. foram obtidos pelo processo de destilação-extração simultânea usando um aparato de Likens-Nickerson (2h) e npentano como solvente. A fração orgânica foi analisada por Cromatografia Gasosa acoplada a Espectrometria de Massas (CG/EM) (Figura 3).

Figura 3 - Obtenção do concentrado volátil das espigas de Piper aduncum L. por destilação-extração simultânea usando um aparato de Likens-Nickerson

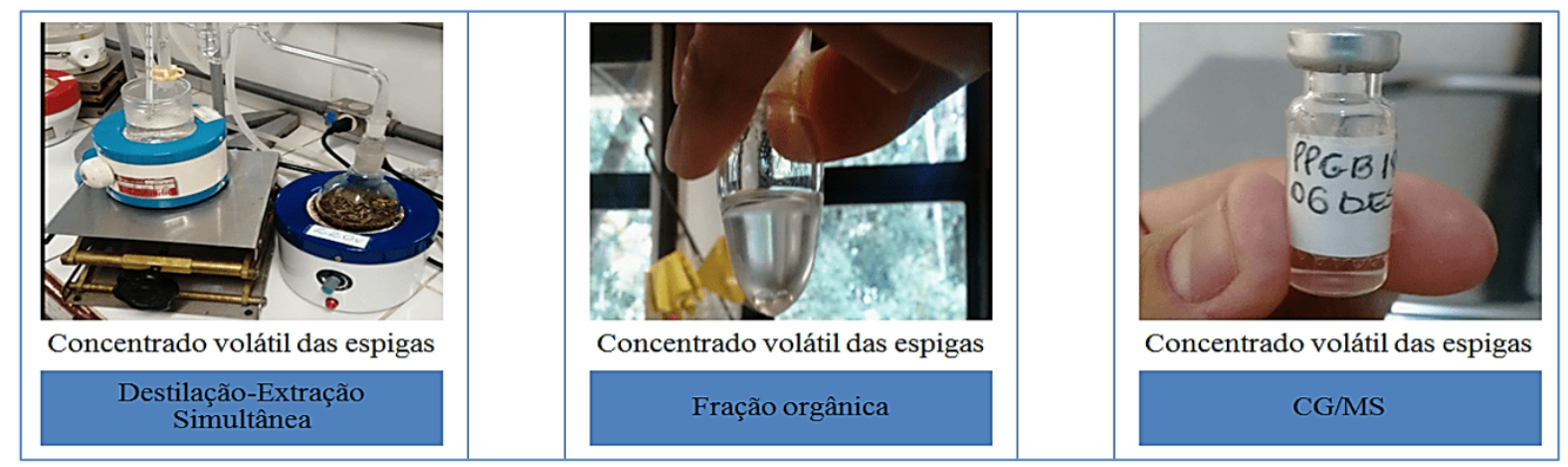

Fonte: Autor. 


\subsection{OBTENÇÃO DO ÓLEO VOLÁTIL}

A extração do óleo volátil das folhas $(30 \mathrm{~g})$ de Piper aduncum L., foi realizada no Laboratório de Fitoquímica por hidrodestilação, em aparelho de Clevenger modificado, foram utilizadas mantas de aquecimento, para balões de $1 \mathrm{~L}$ cada, acoplada a um sistema de refrigeração para manutenção da água de condensação em torno de $12^{\circ} \mathrm{C}$. Após a extração, o óleo foi centrifugado durante 5 minutos a $3000 \mathrm{rpm}$, desidratados com sulfato de sódio $\left(\mathrm{Na}_{2} \mathrm{SO}_{4}\right)$ anidro, e novamente centrifugados nas mesmas condições. Em seguida, os mesmos foram armazenados em ampolas de vidro âmbar, e mantidos em ambiente refrigerado a $5^{\circ} \mathrm{C}$ (Figura 4).

Figura 4 - Obtenção do óleo volátil das folhas Piper aduncum L. por hidrodestilação, em aparelho de Clevenger modificado.

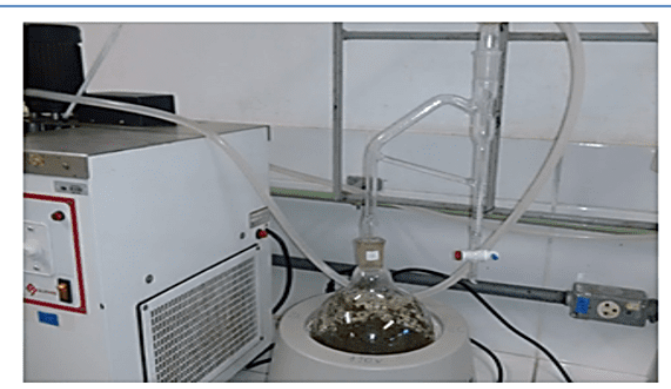

A extração do óleo volátil

Hidrodestilação, em aparelho de Clevenger modificado

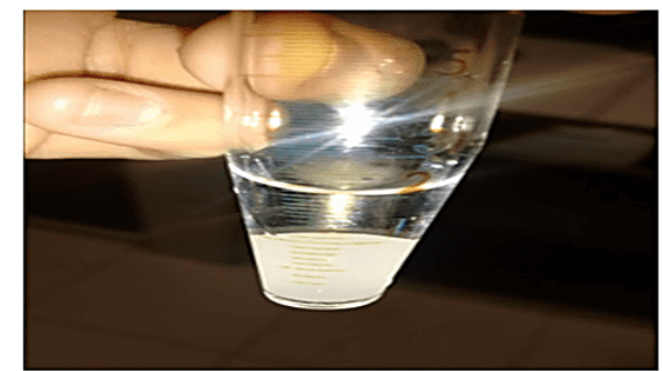

A extração do óleo volátil

Centrifugação e desidratação com $\mathrm{Na}_{2} \mathrm{SO}_{4}$

Fonte: Autor.

\subsection{DETERMINAÇÃO DA UMIDADE RESIDUAL}

A porcentagem de água nas amostras estudadas foi determinada através do analisador de umidade por infravermelho.

\subsection{CÁLCULO DO RENDIMENTO (\%) DO ÓLEO EXTRAÍDO}

O rendimento (\%) do óleo volátil extraído da biomassa vegetal foi obtido do material seco e base livre de umidade (BLU). O rendimento bruto em óleo foi calculado através 
da relação do volume do óleo obtido com a massa do material vegetal utilizado no processo de extração.

\section{$R=\frac{\text { volume de óleo obtido }(\mathrm{mL})}{\text { massa do material botánico }(\mathrm{g})} \times 100$}

O calculo do rendimento em óleo para base do material livre de umidade (BLU) foi obtido através da relação entre massa, óleo e umidade:

$$
R=\frac{\text { volume de óleo obtido }(\mathrm{mL})}{\text { massa do material botânico }(g)-\left(\frac{\text { massa do material botanico x ramiada }}{100 \%}\right)} \times 100
$$

\subsection{ANÁLISE DOS CONSTITUINTES QUÍMICOS DO ÓLEO VOLÁTIL}

$2 \mu \mathrm{l}$ do óleo volátil obtido por hidrodestilação foram diluídos em 0,5 $\mathrm{ml}$ de hexano (UVHPLC) 99,9\% para análise por Cromatografia Gasosa acoplada a Espectrometria de Massa (CG/EM). A análise do óleo volátil foi efetuada no laboratório Adolpho Ducke (LAD), do MPEG por Cromatografia Gasosa acoplada a Espectrometria de Massa (CG/EM) em sistema Shimatzu QP Plus-2010 equipado com coluna capilar de sílica DB-5MS (30 m x 0,25 mm; 0,25 $\mu \mathrm{m}$ de espessura do filme) nas seguintes condições operacionais: gás de arraste: hélio, em velocidade linear de $36,5 \mathrm{~cm} / \mathrm{s}$; tipo de injeção: sem divisão de fluxo ( $2 \mu \mathrm{L}$ de óleo em $1 \mathrm{~mL}$ de hexano); temperatura do injetor: 250 ${ }^{\circ} \mathrm{C}$, programa de temperatura: $60-250 \stackrel{\circ}{\circ}$, com gradiente de $3^{\circ} \mathrm{C} / \mathrm{min}$; temperatura da fonte de íons e outras partes $220^{\circ} \mathrm{C}$. O filtro de quadrupolo varreu na faixa de 39 a 500 daltons a cada segundo. A ionização foi obtida pela técnica de impacto eletrônico a $70 \mathrm{eV}$. 


\subsection{IDENTIFICAÇÃO DOS CONSTITUINTES VOLÁTEIS}

A identificação dos componentes do aroma e do óleo volátil foi baseada no índice de retenção linear (IR) calculado em relação aos tempos de retenção de uma série homóloga de n-alcanos injetados nas mesmas condições das análises, e no padrão de fragmentação observados nos espectros de massas, por comparação destes com amostras autenticas existentes nas bibliotecas do sistema de dados e da literatura (ADAMS, 2007).

\section{RESULTADOS E DISCUSSÃO}

Para a extração de óleo volátil por hidrodestilação das folhas Piper aduncum utilizouse $60,51 \mathrm{~g}$ de folhas secas e trituradas. Os rendimentos de óleo volátil das folhas secas obtidos por hidrodestilação foi de 3,49\%, segundo Maia et al., (1998) a espécie para a Região Amazônica, apresenta rendimentos de 0,66 a 3,4\% em biomassa seca e para outras regiões do País, estes valores são consideravelmente menores, com presença de outros compostos majoritários, sugerindo uma influência de fatores fisiográficos e genéticos na produção do dilapiol (POTZERNHEIM et al., 2012).

Na Figura 5 são mostrados os perfis cromatográficos do aroma das espigas de Piper aduncum $L$. obtido pelo processo de destilação-extração simultânea e do óleo volátil de folhas obtido por hidrodestilação e a constituição química do aroma e do óleo volátil pode ser vista na Tabela 1. 
Figura 5 - Perfis cromatográficos de aroma das espigas de Piper aduncum L. obtido pelo processo de destilação-extração simultânea $(A)$ e do óleo volátil das folhas obtido por hidrodestilação.
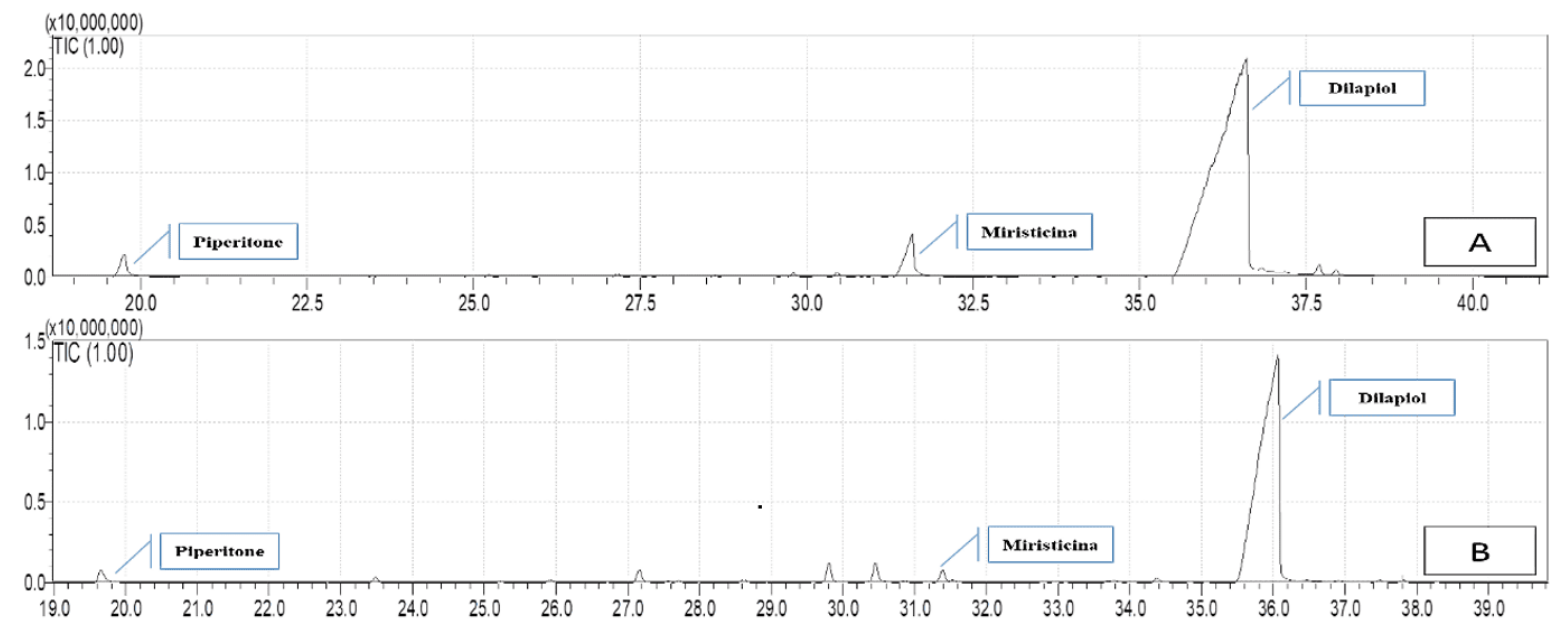

Fonte: Autor

Tabela 1. Constituintes químicos do aroma das espigas de Piper aduncum $\mathrm{L}$. obtido pelo processo de destilação-extração simultânea e do óleo volátil de folhas obtido por hidrodestilação.

\begin{tabular}{|c|c|c|c|}
\hline & & Aroma (DES) & Óleo volátil (HD) \\
\hline IR & Constituintes & $(\%)$ & $(\%)$ \\
\hline 949 & $\alpha$-Tujeno ${ }^{a}$ & 0,09 & - \\
\hline 957 & $\alpha-$ Pineno $^{a}$ & 1,94 & - \\
\hline 1002 & $\beta$-Pineno a & 1,01 & - \\
\hline 1025 & $\alpha$-Felandreno ${ }^{a}$ & 0,23 & - \\
\hline 1036 & $\alpha$-Terpineno ${ }^{a}$ & 0,23 & - \\
\hline 1048 & Silvestreno ${ }^{a}$ & 1,58 & - \\
\hline 1055 & $(Z)-\beta$-Ocimeno ${ }^{b}$ & - & 0,97 \\
\hline 1065 & $(E)-\beta$-Ocimeno ${ }^{b}$ & - & 3,47 \\
\hline 1077 & $\mathrm{Y}$-Terpineno ${ }^{c}$ & 1,51 & 0,24 \\
\hline 1106 & Terpinoleno $^{c}$ & 0,34 & 0,08 \\
\hline
\end{tabular}




\begin{tabular}{|c|c|c|c|}
\hline 1141 & Allo-ocimeno ${ }^{b}$ & - & 0,42 \\
\hline 1115 & Linalol $^{a}$ & 0,19 & - \\
\hline 1185 & 4-Terpinenol ${ }^{c}$ & 0,73 & 0,39 \\
\hline 1269 & Piperitona $^{c}$ & 2,06 & 1,49 \\
\hline 1350 & Biciclogermacreno $^{b}$ & - & 0,41 \\
\hline 1385 & $\alpha-$ Copaeno $^{c}$ & 0,14 & 0,06 \\
\hline 1429 & $(E)$-Cariofileno ${ }^{c}$ & 0,26 & 1,24 \\
\hline 1443 & $\mathrm{Y}^{- \text {Elemeno }^{\mathrm{b}}}$ & - & 0,14 \\
\hline 1466 & $\alpha-$ Humuleno $^{c}$ & 0,1 & 0,31 \\
\hline 1495 & D-Germacreno & 0,24 & 1,79 \\
\hline 1511 & Limonen-6-ol a & 0,28 & - \\
\hline 1522 & $\Delta$-Amorfeno ${ }^{\mathrm{C}}$ & 0,04 & 0,14 \\
\hline 1540 & Miristicina $^{c}$ & 4,71 & 1,21 \\
\hline 1658 & Dilapiol $^{\mathrm{C}}$ & 83,17 & 82,71 \\
\hline 1699 & Apiol $^{c}$ & 0,24 & 0,22 \\
\hline
\end{tabular}

Legenda: IR- Índice de Retenção; a- Constituintes presentes no aroma; bConstituintes presentes no óleo volátil; c- Constituintes presentes no aroma e no óleo volátil; (DES)- Destilação-Extração Simultânea; (HD)- Hidrodestilação; NegritoConstituintes majoritários. Fonte: Autor.

Ao todo foram detectados 25 constituintes, sendo que: apenas 12 destes foram comuns ao aroma e ao óleo em ambas as técnicas e partes da planta utilizada; 8 se mostraram exclusivos à constituição do aroma e 5 constituintes presentes apenas no óleo volátil. Quando observamos na Tabela 1 os componentes em comum que apresentaram como majoritários para o aroma e óleo volátil são: piperitona, miristicina e dilapiol que somados constituem $89,94 \%$ no aroma e $85,41 \%$ no óleo volátil. O dilapiol possui forte ação inseticida e bactericida, juntamente com a miristicina, um fenilpropanide com propriedades narcóticas, tóxicas para mamíferos e insetos (FAZOLIN, 2007). 
A diferença quantitativa do teor de metabólitos secundários nas diferentes técnicas e partes da planta utilizada pode estar relacionada com diversos fatores, como local e principalmente a parte da planta utilizada (FALKENBERG et al., 1999).

A presença ou ausência de constituintes a explicação não pode ser tão simples, pois, componentes como o $\alpha$-tujeno presentes apenas no aroma, quando submetido a altas temperaturas da hidrodestilação, pode transformar-se em y-Terpineno e 4-Terpineol. Da mesma forma, hidrocarbonetos sesquiterpênicos também podem sofrer diversos rearranjos por causas térmicas, fotoquímicas (SCHOSSLER et al., 2009).

\section{CONCLUSÕES}

A extração de óleo volátil por hidrodestilação mostrou-se adequada e eficiente para a obtenção de óleo volátil de Piper aduncum com rendimento compatível com os existentes na literatura, para este método de extração. A análise dos constituintes voláteis por CG/EM permitiu a identificação de três constituintes principais em ambas as partes dos vegetais: piperitona, miristicina e dilapiol que somados constituem $89,94 \%$ no aroma e $85,41 \%$ no óleo volátil.

\section{REFERÊNCIAS}

ADAMS, R. P. Identification of essential oil components by gas chromatography/mass spectroscopy. $4^{\text {th }}$ ed., Allured Publishing Corporation, Carol Stream, 2007.

ALI, K. M., CHATTERJEE, K., DE, D., JANA, K., BERA, T. K., GHOSH, D. Inhibitory effect of hydro methanolic extract of seed of Holarrhena antidysenterica on alphaglucosidase activity and postprandial blood glucose level in normoglycemic rat. Journal of Ethnopharmacology, v.135, p.194-196, 2011.

ALVES, H. M. A Diversidade química das plantas como fonte de fitofármacos. Cadernos Temáticos de Química Nova na Escola, v.3, p.10-15, 2007.

FALKENBERG, M. B., SANTOS, R. I., SIMÕES, C. M. O. Introdução à análise fitoquímica. $5^{\text {th }}$ ed. Florianópolis: Editora.1999. 
FAZOLIN, M. Utilização de óleos essenciais no controle de pragas do abacaxi. Inf. Embrapa Acre n" 21; 4 p.; 2007

GUERRINI, A.; SACCHETTI, G.; ROSSI, D.; PAGANETTO, G.; MUZZOLI, M. A.; ANDREOTTI, Tognolin, M.; E.; MALDONADO, M. E.; BRUNI, R. Bioactivities of Piper aduncum L. and Piper obliquum Ruiz \& Pavon (Piperaceae) essential oils from Eastern Ecuador. Environmental Toxicology and Pharmacology, v.27, n. 1, p.39-48, 2009.

GYLLENHAAL, C., KADUSHIN, M. R., SOUTHAVONG, B., SYDARA, K., BOUAMANIVONG, S., XAIVEU, M., XUAN, L.T., HIEP, N. T., HUNG, N. V., LOC, P. K., DAC, L. X., BICH, T. Q., CUONG, N. M., LY, H. M., ZHANG, H. J., FRANZBLAU, S. G., XIE, H., RILEY, M. C., ELKINGTON, B. G., NGUYEN, H. T., WALLER, D. P., MA, C. Y., TAMEZ, P., TAN, G. T., PEZZUTO, J. M., SOEJARTO, D. D. Ethnobotanical approach versus random approach in the search for new bioactive compounds: support of a hypothesis. Pharmaceutical Biology, v.50, p.30-41, 2012.

MAIA, J. G. S.; ZOHHBI, M. G. B.; ANDRADE, H. H. A.; SANTOS, A. S.; SILVA, M. H. L.; LUZ, A. I. R.; BASTOS, C. N. Constituents of the essential oil of Piper aduncum L. growing wild in the Amazon region. Flavour and Fragrance Journal v.13, p.269-272, 1998.

MESQUITA, J. M. O.; CAVALEIRO, C.; CUNHA, A. P.; LOMBARDI, J. A.; OLIVEIRA, A. B. Estudo comparativo dos óleos voláteis de algumas espécies de Piperaceae. Revista Brasileira de Farmacognosia, v.15, p.6-12, 2005.

MISNI, N.; SULAIMAN, S.; OTHMAN, H. BAHARUDIN, O. Repellency of essential oil of Piper aduncum against Aedes albopictus in the laboratory. . Journal of the American Mosquito Control Association, v.25, n. 4, p.442-447, 2009.

PAN, S. Y., PAN, S., YU, Z. L., MA, D. L., CHEN, S. B., FONG, W. F., HAN, Y. F., KO, K. M. New perspectives on innovative drug discovery: an overview. Journal of Pharmacy \& Pharmaceutical Sciences, v.13, p.450-471, 2010. 
POTZERNHEIM, M. C. L.; BIZZO, H. R.; SILVA, J. P.; VIEIRA, R. F. Chemical characterization of essential oil constituents of four populations of Piper aduncum $\mathrm{L}$. from Distrito Federal; Brazil. Biochemical Systematics and Ecology, v. 42, p.25-31, 2012.

SANINI, S.; MASSAROLI, A.; KRINSKI, D.; BUTNARIU, A. R. Essential oil of spiked pepper, Piper aduncum L. (Piperaceae) for the control of caterpillar soybean looper, Chrysodeixis includens Walker (Lepidoptera: Noctuidae). Brazilian Journal of Botany, 2017.

SANTOS, T. G.; REBELO, R. A.; DALMARCO, E. M.; GUEDES, A.; GASPER, A. L.; BELLA CRUZ, A.; SCHMIT, A. P.; BELLA CRUZ, R. C; STEINDEL, M.; NUNES, R. K. Composição química e avaliação da atividade antimicrobiana do óleo essencial das folhas de Piper malacophyllum (C. Presl.) C. DC.. Química Nova (Impresso), v.35, n. 4, p.477-481, 2012.

SCHOSSLER, P., SCHNEIDER, G. L., WUNSCH, D., SOARES, G. L. G., ZINI, C. A. Volatile compounds of baccharis punctulata, baccharis dracunculifolia and eupatorium laevigatum obtained using solid phase microextraction and hydrodistillation. Journal Brazilian Chemical Society, v.20, n.2, p. 277-287, 2009.

SOUSA, P.J.C.; BARROS, C. A. L.; ROCHA, J.C.S.; LIRA, D. S.; MONTEIRO, G. M.; MAIA, J.G.S. Avaliação toxicológica do óleo essencial de Piper aduncum L. Revista Brasileira de Farmacognosia, v.18, p.217-221, 2008.

Enviado: Março, 2020.

Aprovado: Outubro, 2020. 